\title{
Modelling the kinetics of hexavalent molybdenum (Mo6+) reduction by the Serratia sp. strain MIE2 in batch culture
}

\begin{abstract}
In the present work, the kinetics of hexavalent molybdenum reduction by the Serratia sp. strain MIE2 were investigated using several kinetic models, such as Monod, Haldane, Teissier, Aiba, Yano, Han and Levenspiel and Luong. The statistical analysis showed that the best model was Teissier, which had the lowest RMSE and AICc values, the highest adjusted $R^{2}$ values, and an $F$ test and with a bias factor and an accuracy factor nearest to unity (1.0). The calculated value for the Teissier constants, such as $p_{\max }, K_{s}$ and $K_{i}$, was $0.506 \mu \mathrm{mol} \mathrm{Mo-}$ blue $\mathrm{h}^{-1}, 6.53 \mathrm{mM}$ and $29.41 \mathrm{mM}$, respectively. The effect of heavy metals showed that hexavalent molybdenum reduction by the strain MIE2 was inhibited by silver, mercury and copper with a total inhibition of 96, 97, and $45 \%$, respectively, at a concentration of $1 \mathrm{ppm}$. Otherwise, the Mo-reducing enzyme was inhibited by mercury and zinc with an inhibition of 88 and $65 \%$, respectively. Most of the respiratory inhibitors did not inhibit the Mo-reducing enzyme activity, indicating that the respiratory system in this bacterium is not the site of the hexavalent molybdenum reduction. The results obtained from this study could be useful for estimating the relationship between molybdenum-blue production and the molybdate concentration, which may be important during the up scaling of the molybdenum bioremediation process.
\end{abstract}

Keyword: Bioremediation; Molybdenum; Modelling kinetics; Heavy metals; Respiratory inhibitors 